\title{
Upper Airway Findings and Markers of Lung Disease Progression in Patients with Cystic Fibrosis
}

\author{
Luciane Mazzini Steffen ${ }^{1} \quad$ Luise Sgarabotto Pezzin ${ }^{1}$ Natassia Sulis ${ }^{2} \quad$ Nedio Steffen ${ }^{1}$ \\ Leonardo Araujo Pinto ${ }^{3}$ \\ ${ }^{1}$ Department of Otorhinolaringology, Pontifícia Universidade \\ Católica do Rio Grande do Sul, Porto Alegre, RS, Brazil \\ ${ }^{2}$ Department of Pediatrics, Pontifícia Universidade Católica do Rio \\ Grande do Sul, Porto Alegre, RS, Brazil \\ ${ }^{3}$ Department of Pediatric Pneumology, Pontifícia Universidade \\ Address for correspondence Luise Sgarabotto Pezzin, MD, \\ Department of Otorhinolaringology, Pontifícia Universidade Católica \\ do Rio Grande do Sul, Porto Alegre, RS, 90619900, Brazil \\ (e-mail: lupezzin@gmail.com).
}

Católica do Rio Grande do Sul, Porto Alegre, RS, Brazil

Int Arch Otorhinolaryngol 2020;24(4):e434-e437.

\begin{abstract}
Introduction Cystic fibrosis (CF) is a genetic disease that limits the quality of life mainly due to respiratory symptoms. The relationship between findings of the upper airways and CF lung disease is not yet completely understood.

Objective The aim of the present study is to describe the most frequent nasal findings and pathogens in patients with CF and investigate the association between the findings of the upper respiratory tract and markers of lung disease progression.

Methods Retrospective study in patients with CF from the Pediatric Pulmonology Department who underwent otorhinolaryngological evaluation between 2015 and 2017. Nasal endoscopy and nasal swab collection were part of the evaluation. The severity markers used were: percentage of predicted forced expiratory volume in the first second (FEV1\%), body mass index (BMI) and the Shwachman-Kulczycki (SK) clinical score.

Results A total of 48 patients with CF were included. The mean of the predicted percentage of FEV1\% was $83.36 \pm 30.04$. The average 14 and SK score $89.11 \pm 10.50$. The bacteriology of the nasal swab was positive in 27 (54.1\%) patients. Staphylococcus aureus was positive in 18 patients, Pseudomonas aeruginosa in 5, Pseudomonas cepacea in 3

Keywords

- cystic fibrosis

- respiratory tract infections

- nasal polyps

- bacteriology and Stenotrophomonas maltophila in 1 patient. Nasal polyps were found in nine participants. Nasal polyps were found in nine participants and were associated with lower SK score. Conclusion The pathogens found in the upper airway were, in order: S. aureus, P. aeruginosa, P. cepacea e $S$. maltophila. The presence of polyps in the nasal cavity showed statistical significance and appears to have association with the prognostic factor measured by the SK score.
\end{abstract}

\section{Introduction}

Cystic fibrosis (CF) is an autosomal recessive disorder, caused by mutations in the cystic fibrosis transmembrane conductance regulator gene (CFTR). Cystic fibrosis may have various phenotypic expressions in upper airways and lungs. It affects different systems and may cause life-limiting complications. ${ }^{1-4}$

received

February 20, 2019

accepted

October 20, 2019
DOI https://doi.org/

10.1055/s-0039-3402434. ISSN 1809-9777.
The incidence is $\sim 1$ to 2,000 live births in Caucasians, being less common in African-Americans $(1: 17,000)$ and in Eastern countries $(1: 90,000)$. The number of registered patients with $\mathrm{CF}$ has been growing annually worldwide. This is associated with the introduction of the national or local programs of neonatal screening. ${ }^{5}$

Copyright @ 2020 by Thieme Revinter Publicações Ltda, Rio de Janeiro, Brazil

License terms

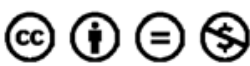


Cystic fibrosis is associated with the production of thick secretions, and obstruction exocrine glands in the affected organs. $^{6-8}$ The respiratory system is mainly responsible for the severity of the disease and the highest morbidity and mortality. The upper airways exhibit a range of conditions such as sinusitis, nasal polyps and mucocele. Lung disease in CF is characterized by respiratory infection and colonization by bacteria that lead to irreversible tissue damage. The microorganisms more frequently involved are: Staphylococcus aureus (SA), Pseudomonas aeruginosa (PA), Pseudomonas cepacea (PC) and Stenotrophomonas maltophilia (SM). ${ }^{9-12}$

The relationship between the bacteria of the upper or lower respiratory tract is not yet completely understood. Some centers recommend aggressive treatment to infection as well as colonization of the sinuses, especially if there is presence of PA or PC. ${ }^{13-17}$ To monitor the progression of the disease, some parameters have been currently used as body mass index ([BMI] absolute value or percentile), forced expiratory volume in the first second (FEV1\%) and the Shwachman-Kulczycki (SK) score. ${ }^{18}$

The present study aims to describe the most frequent nasal findings and pathogens in patients with cystic fibrosis. In addition, we investigated the association between the findings of the upper respiratory tract (URT) and markers of lung disease progression.

\section{Method}

This was a retrospective cross-sectional study, involving patients with confirmed diagnosis of $\mathrm{CF}$ in accordance with the criteria of the CF Foundation. Patients were followed-up in the CF Clinic at a University Hospital. All of the patients underwent otorhinolaryngological evaluation between 2015 and 2017.

The upper airway evaluation included, among the tests, the collection of nasal material through a swab and videonasofibroscopy. All of the patients were evaluated in the outpatient Clinic of Otorhinolaryngology of the same Hospital. The collection was obtained through the nasal swab. (Stuart Swabs, Absorve/CRAL, Sao Paulo/SP, Brazil). Nasal speculum was sterilized in autoclave for opening the nasal cavity and then the swab was inserted into the nostril to the posterior portion (posterior nasal apertures) and directed to the middle meatus. This gathering was preceded by the examination of videonasofibroscopy to prevent contamination of the URT. The material was sent immediately to the microbiology laboratory.

The videonasofibroscopy has been performed using a Mashida ENT 30 PIII flexible fiber-optic nasopharyngolaryngoscope with $3.2 \mathrm{~mm}$ in diameter (Mashida, Madrid, Spain), coupled to a Toshiba video camera model IKM41A (Toshiba, Tokyo, Japan) and transmitted to a LG TV model 14FK3RB (LG, Seoul, South Korea). A halogen light source of $250 \mathrm{~W}$ was used. The present survey allowed the direct assessment of the nasal cavity status. The parameters observed in the nasal endoscopy were: presence, absence and aspect of the meatus secretion, the presence or absence of pharyngeal tonsil and nasal polyps. The results of the oropharyngeal/sputum collection were obtained from the elec- tronic patient record, respecting the maximum interval of 90 days, when they perform the routine reviews of multidisciplinary outpatient clinic (Pneumology, Pediatric Gastroenterology and Physical Therapy). Markers of disease severity and progression as FEV1\%, BMI, and clinical SK score rating, in addition to the gene mutations, have also been extracted from the records of the patients.

Newborns and young infants without indication of otorhinolaryngological evaluation were excluded from the study. The present study was submitted and approved by the Ethics Committee of the University (Approval Number 1,294,834)

The data are described in mean and standard deviation (SD) for continuous variables, or absolute number and percentage (\%) for qualitative variables. For the association between the variables, the following statistical tests were used: the chi-squared test for categorical outcomes; and the Student $t$-test for numerical outcomes. The considered statistical significance was of $p<0.05$.

\section{Result}

Out of 91 patients who are followed in the Cystic Fibrosis Clinic of the Hospital, 48 were selected to participate in the study. From the total of patients in follow-up, those who had not performed otorhinolaryngological evaluation were excluded.

In the sample of 48 patients, $30(62.5 \%)$ were male. The average age was 12.15 years old \pm 6.60 . The average percentage of predicted values of FEV1\% was $83.36 \pm 30.04$. The average BMI percentile was $52.10 \pm 30.14$ and the average SK score was $89.11 \pm 10.50$. (-Table 1 )

The pharyngeal tonsils were present in $38(79.1 \%)$ of the participants, in which 26 (68.4\%) were level 1, 9 (23.6\%) were level 2 , and $3(7.8 \%)$ were level 3 . No patient presented level 4 tonsils. The bacteriology of the nasal swab was positive in 26 (54.1\%) patients, where 22 were SA, two were PA, one was Burkholderia cepacea, and one was SM. In 22 patients (45.8\%) the result of the culture was negative.

Considering the standard method used on most of the centers (oropharynx swab or sputum), the colonization showed a pattern similar to nasal collection: positive in 27 (56.2\%) patients, in which 18 were SA, 5 were PA, 3 were PC, and SM was positive in 1 patient. The culture was negative in 21 (43.7\%) participants. In the present study, patients who had positive colonization by the traditional method (oropharynx/ sputum), had a statistically significant chance of being identified also by the culture of the nasal cavity $(p<0.001)$. However, the association is not perfect, and it showed low correlation for detection of gram-negative germs.

The presence of nasal polyps was significantly more frequent in older children. Nasal polyps were observed in 9 participants, adults and children, at an average age of $17.67 \pm 5.65$ years old, while 39 were negative with an average age of $10.87 \pm 6.19$ ( $p=0.004$ ) years old. When the presence of polyps is used as a disease marker in nasal endoscopy, there is a strong association between the presence of polyps and the SK score. The FEV1\% showed an average of $88.87 \pm 26.51$ in patients without polyps, and $71.88 \pm 33.50$ in those with nasal polyps, not reaching 
Table 1 Clinical data of patients with cystic fibrosis included in the upper airway analysis

\begin{tabular}{|l|l|}
\hline & Total \\
\hline Patients, n (\%) & $48(100)$ \\
\hline Age (years old) \pm SD & $12.15 \pm 6.60$ \\
\hline Gender (male), n (\%) & $30(62.5)$ \\
\hline FEV1\%, average \pm SD & $83.36 \pm 30.04$ \\
\hline pBMI, average \pm SD & $52.10 \pm 30.14$ \\
\hline SK score, average \pm SD & $89.11 \pm 10.50$ \\
\hline Nasal swab, n (\%) & $96(100)$ \\
\hline Oropharynx swab & $48(100)$ \\
\hline Nasal polyp, n (\%) & $9(18.7)$ \\
\hline Pharyngeal tonsil, n (\%) & $38(79.1)$ \\
\hline Level 1 & $26(68.4)$ \\
\hline Level 2 & $9(23.6)$ \\
\hline Level 3 & $3(7.8)$ \\
\hline Secretion RN, n (\%) & \\
\hline Mucoid & $12(25)$ \\
\hline Purulent & $5(10.4)$ \\
\hline Absent & $31(64.5)$ \\
\hline Secretion LN, n (\%) & $11(22.9)$ \\
\hline Mucoid & $9(18.7)$ \\
\hline Purulent & $28(58.3)$ \\
\hline Absent & \\
\hline
\end{tabular}

Abbreviations: FEV1\%, forced expiratory volume in one second (percentage); LN, left nostril; pBMI, body-mass index-percentile; RN, right nostril; SD, standard deviation; SK score, Shwachman-Kulczycki score.

statistical significance $(p=0.136)$. The average BMI percentile was $53.97 \pm 31.39$ in those without polyps, and $44.78 \pm 23.61$ in the ones with nasal polyps ( $p=0.414$ ). The average of the SK score was $92.57 \pm 5.38$ in those with absence of polyps, and $79.50 \pm 9.66$ in the ones with it, showing statistical significance $(p<0.001,-$ Table 2)

\section{Discussion}

The results of the upper and lower airways culture have been subject of study in patients with cystic fibrosis to clarify the

Table 2 The presence of nasal polyp associated with markers of severity and progression of the disease

\begin{tabular}{|l|l|l|l|}
\hline & $\begin{array}{l}\text { Positive Polyp } \\
\text { Average } \pm \text { SD }\end{array}$ & $\begin{array}{l}\text { Negative Polyp } \\
\text { Average } \pm \text { SD }\end{array}$ & $p$-value \\
\hline FEV1\% & $71.88 \pm 33.50$ & $88.87 \pm 26.51$ & 0.136 \\
\hline pBMI & $44.78 \pm 23.61$ & $53.97 \pm 31.39$ & 0.414 \\
\hline SK score & $79.50 \pm 9.66$ & $92.57 \pm 5.38$ & $<0.001$ \\
\hline
\end{tabular}

Abbreviations: FEV1\%, forced expiratory volume in one second (percentage); pBMI, body-mass index percentile; SD, standard deviation; SK score, Shwachman-Kulczycki score. possibility of colonization of the upper airway before or with the lower airway. Hansen et $\mathrm{al}^{17}$ refer to the possibility of the nasal cavity to serve as a bacterial reservoir and there might be migration of pathogens to the lower respiratory tract, which could justify the clinical worsening of these patients. Nonetheless, it has not yet been possible to establish sufficient evidence for this relation. The present study showed similarity of germs found in both airway sites evaluated, in accordance with the literature reports. ${ }^{15,16,19}$

In the present study, the comparison of bacteriology between the oropharynx and the nasal cavity allows to check that the level of concordance, since $83.3 \%$ had SA in both nasal and oropharyngeal samples. However, the correlation between gram-negative germs was low (22.2\%), but the number of patients with positive culture for these last germs may have been insufficient. This result demonstrates that the nasal swab can be considered a sensitive method for detection of the upper airway colonization. It is associated with the colonization of the lower airway especially when we observe the data for SA, which was the most frequent germ. Furthermore, it is relevant to emphasize that the germs mentioned above have been described as causal pathogens of chronic pulmonary infection. ${ }^{8,12,20-22}$

The presence of nasal polyps in this research was of $18.7 \%$, in the total sample. However, when we stratify among adults and children, this number decreases to $10.4 \%$ in the sample of children, corroborating with the study of Henriksson et al, who report a finding in $\sim 10 \%$ of children with cystic fibrosis. ${ }^{23}$

The endoscopic examination of the nasal cavity showed the presence of nasal polyps and, when associated with the SK score, revealed the predictive value of severity of lung disease, agreeing with the study of Freitas et $\mathrm{al}^{11}$, which also features statistical significance between the data of nasofibroscopy and the SK score, meaning that patients with more severe clinical conditions feature more important changes in nasal endoscopy. From our study, it is still not possible to conclude whether changes in the upper airways precede the development of pulmonary disease. ${ }^{15,24,25}$

The small number of participants may be associated with the lack of statistical significance in some of the associations tested in the present study. On the other hand, CF is still considered a rare disease, handled almost exclusively on CF centers in tertiary hospitals, which makes it difficult to include a large number of patients. Two of the present findings may have clinical relevance: the usefulness of nasal swab for identification of SA, and the association between nasal polyps with factors of progression of lung disease. These findings suggest a significant association between the upper and lower airways disease in CF. Therefore, the upper airways assessment should be considered as an important opportunity for the identification of germs or signs associated with the progression of the disease. ${ }^{7}$

Many studies have shown the importance of SA in the progression of lung disease. Even more recently, methicillinresistant SA (MRSA) has been implicated in rapid disease progression. Cases of MRSA were not observed in the present study. However, larger samples might identify this germ and its relevance. ${ }^{26,27}$ Considering the upper airway findings, we may suggest that patients with cystic fibrosis should be 
routinely evaluated by the ENT specialist, since the upper airway seems to contribute to the early identification of pathogens which are responsible for lower airway complications. In addition, the collection and culture of secretions of the nostril can contribute to identify some relevant infections of patients with $\mathrm{CF}$, especially in cases of positive cultures for SA. ${ }^{26}$

\section{Conclusion}

The pathogens found in the upper airway, according to the frequency, were: SA PA, PC, and SM. The presence of polyps in the nasal cavity showed statistical significance and appears to have association with the prognostic factor measured by the clinical SK score.

Conflicts of Interests

The Authors Have No Conflicts Of Interests To Declare.

\section{References}

1 Ratjen F, Döring G. Cystic fibrosis. Lancet 2003;361(9358):681-689

2 Castellani C, Assael BM. Cystic fibrosis: a clinical view. Cell Mol Life Sci 2017;74(01):129-140

3 Flume PA, O'Sullivan BP, Robinson KA, et al; Cystic Fibrosis Foundation, Pulmonary Therapies Committee. Cystic fibrosis pulmonary guidelines: chronic medications for maintenance of lung health. Am J Respir Crit Care Med 2007;176(10):957-969

4 Weber SAT, Iyomasa RM, Correa CC, Florentino WNM, Ferrari GF. Nasal polyposis in cystic fibrosis: follow-up of children and adolescents for a 3-year period. Rev Bras Otorrinolaringol (Engl Ed) 2017;83(06):677-682

5 Cística GBdEeF. Relatório do Registro Brasileiro de Fibrose Cística 2014.2014

6 Plant BJ, Goss CH, Plant WD, Bell SC. Management of comorbidities in older patients with cystic fibrosis. Lancet Respir Med 2013;1 (02):164-174

7 Aanæs K. Bacterial sinusitis can be a focus for initial lung colonisation and chronic lung infection in patients with cystic fibrosis. J Cyst Fibros 2013;12(Suppl 2):S1-S20

8 Ribeiro JD, Fischer GB. Doenças pulmonares obstrutivas crônicas na criança. J Pediatr 2015;91:S11-S25

9 Rosenfeld M, Emerson J, Accurso F, et al. Diagnostic accuracy of oropharyngeal cultures in infants and young children with cystic fibrosis. Pediatr Pulmonol 1999;28(05):321-328

10 Ribeiro JD, Ribeiro MA, Ribeiro AF. Controvérsias na fibrose cística-do pediatra ao especialista. J Pediatr (Rio J) 2002;78 (Suppl 2):S171-S186

11 Freitas MR, Vasconcelos DN, Freitas AE, Maia Filho JH, Castro e Silva Cd. Nasal endoscopic and CT scan alterations of the paranasal sinuses as predictors of severity in patients with cystic fibrosis. Rev Bras Otorrinolaringol (Engl Ed) 2013;79(04):480-486

12 Rivas Caldas R, Boisramé S. Upper aero-digestive contamination by Pseudomonas aeruginosa and implications in Cystic Fibrosis. J Cyst Fibros 2015;14(01):6-15

13 Mainz JG, Naehrlich L, Schien M, et al. Concordant genotype of upper and lower airways $\mathrm{P}$ aeruginosa and $\mathrm{S}$ aureus isolates in cystic fibrosis. Thorax 2009;64(06):535-540

14 Robertson JM, Friedman EM, Rubin BK. Nasal and sinus disease in cystic fibrosis. Paediatr Respir Rev 2008;9(03):213-219

15 Umetsu DT, Moss RB, King VV, Lewiston NJ. Sinus disease in patients with severe cystic fibrosis: relation to pulmonary exacerbation. Lancet 1990;335(8697):1077-1078

16 Muhlebach MS, Miller MB, Moore C, Wedd JP, Drake AF, Leigh MW. Are lower airway or throat cultures predictive of sinus bacteriology in cystic fibrosis? Pediatr Pulmonol 2006;41(05):445-451

17 Hansen SK, Rau MH, Johansen HK, et al. Evolution and diversification of Pseudomonas aeruginosa in the paranasal sinuses of cystic fibrosis children have implications for chronic lung infection. ISME J 2012;6(01):31-45

18 Rudkjøbing VB, Aanaes K, Wolff TY, von Buchwald C, Johansen HK, Thomsen TR. An exploratory study of microbial diversity in sinus infections of cystic fibrosis patients by molecular methods. J Cyst Fibros 2014;13(06):645-652

19 Ratjen F, Walter H, Haug M, Meisner C, Grasemann H, Döring G. Diagnostic value of serum antibodies in early Pseudomonas aeruginosa infection in cystic fibrosis patients. Pediatr Pulmonol 2007;42(03):249-255

20 da Silva Filho LV, Tateno AF, Martins KM, et al. The combination of PCR and serology increases the diagnosis of Pseudomonas aeruginosa colonization/infection in cystic fibrosis. Pediatr Pulmonol 2007;42(10):938-944

21 Ribeiro JD. Ribeiro MÂGdO, Ribeiro AF. Controvérsias na fibrose cística: do pediatra ao especialista. J Pediatr (Rio J) 2002; 78:171-186

22 Gibson RL, Burns JL, Ramsey BW. Pathophysiology and management of pulmonary infections in cystic fibrosis. Am J Respir Crit Care Med 2003;168(08):918-951

23 Henriksson G, Westrin KM, Karpati F, Wikström AC, Stierna P, Hjelte L. Nasal polyps in cystic fibrosis: clinical endoscopic study with nasal lavage fluid analysis. Chest 2002;121(01):40-47

24 Taylor CJ, McGaw J, Howden R, Duerden BI, Baxter PS. Bacterial reservoirs in cystic fibrosis. Arch Dis Child 1990;65(02):175-177

25 Stollar F, Adde FV, Cunha MT, Leone C, Rodrigues JC. ShwachmanKulczycki score still useful to monitor cystic fibrosis severity. Clinics (São Paulo) 2011;66(06):979-983

26 Bittencourt PH, Pimentel CSS, Bonfim BS, Almeida CD, Marostica PJC, de Souza ELS. Incidence and treatment of methicillin-resistant Staphylococcus aureus infection in cystic fibrosis patients: a cohort study. Pediatr Pulmonol 2016;51:S40

27 Smyth AR, Bell SC, Bojcin S, et al; European Cystic Fibrosis Society. European Cystic Fibrosis Society Standards of Care: Best Practice guidelines. J Cyst Fibros 2014;13(Suppl 1):S23-S42 